\title{
The Influence of Service Quality on Clients' Satisfaction and Its Effect on Their Loyalty at PT Bank Aceh, Medan Branch
}

\author{
Budi Irwansyah \\ Endang Sulistya Rini \\ Beby KF Sembiring \\ Fakultas Ekonomi dan Bisnis Universitas Sumatera Utara \\ Email: boboy_daulay@yahoo.com
}

\begin{abstract}
PT. Bank Aceh, Medan Branch, undergoes the decrease in its clients' loyalty which indicated by the increase in non-active clients in the period of 2011-2015. The objective of this research was to find out and analyze the influence of Service Quality on Clients' satisfaction and its effect on their loyalty at PT. Bank Aceh, Medan Branch. The data were gathered by conducting descriptive quantitative survey and distributing questionnaires to 94 respondents and analyzed by using path analysis. The result of the research showed that, simultaneously, tangibles, reliability, responsiveness, assurance, and empathy had positive and significant influence on clients' loyalty. Partially, tangibles had positive and significant influence on clients' loyalty, reliability had positive and significant influence on clients' loyalty, responsiveness had positive and significant influence on clients' loyalty, assurance did not have any positive and significant influence on clients' loyalty, and empathy had positive and significant influence on clients' loyalty at PT. Bank Aceh, Medan Branch. Clients' satisfaction had positive and significant influence on clients' loyalty at PT. Bank Aceh, Medan Branch. Tangibles, reliability, responsiveness, assurance, and empathy directly and indirectly had positive influence on clients' loyalty through clients' satisfaction at PT. Bank Aceh, Medan Branch.
\end{abstract}

Key words: Tangibles, Reliability, Responsiveness, Assurance, Empathy, Satisfaction, Loyalty

\section{PENDAHULUAN}

alam era globalisasi, jumlah jenis dan berbagai produk yang ditawarkan oleh bank cukup bervariasi dan dapat bersaing, sehingga nasabah memiliki ragam pilihan dan alternatif produk dan jasa yang dapat memenuhi kebutuhannya dan berhak memilih sesuai yang nasabah inginkan. Dengan adanya persaingan yang 
terjadi, hal tersebut menuntut para pelaku bisnis perbankan untuk mengeluarkan segala kemampuan yang mereka miliki agar dapat bersaing di pasar.

Setiap pelaku usaha perbankan di tiap kategori bisnis dituntut untuk memiliki kepekaan terhadap setiap perubahan yang terjadi dan menempatkan orientasi kepada kepuasan konsumen sebagai tujuan utama (Kotler, 2008). Perbankan dalam meningkatkan loyalitas nasabah dan memberikan kepuasan kepada nasabah, harus mempelajari terlebih dahulu keinginan dan kebutuhan nasabah pada saat ini dan yang akan datang.

Loyalitas nasabah adalah puncak pencapaian pelaku bisnis perbankan. Nasabah yang puas dan setia tidak akan ragu untuk menjadi penyebar kabar baik yang selalu menyebarkan kebaikan mengenai produk perbankan yang di konsumsinya, untuk mempertahankan nasabah yang loyal memang harus mendapatkan prioritas yang utama dari pada mendapatkan nasabah baru, karena untuk merekrut atau mendapatkan nasabah baru bukanlah hal yang mudah karena akan memerlukan biaya yang banyak, maka sangatlah rugi bila perusahaan melepas nasabah yang telah loyal secara begitu saja.

Tujuan yang utama bank adalah bagaimana membuat nasabah loyal/setia kepada bank, yang terpenting dan mekanisme mencapai loyalitas nasabah. untuk mewujudkan loyalitas nasabah yang dibutuhan bank adalah menciptakan kepuasan nasabah sebagai dasar menciptakan loyalitas. Konsep loyalitas merupakan konsep dasar dalam memahami hubungan pemasaran, karena pada hakekatnya loyalitas berkaitan dengan faktor intenal dalam setiap diri bank. Bagi bank memandang arti penting loyalitas adalah merupakan perwujudan moral yang positif dari nasabah terhadap bank (Calik dan Balta 2006). Loyalitas dapat dipengaruhi oleh kepuasan dengan melihat bahwa keinginan konsumen sudah tercapai atau belum.

Kepuasan nasabah merupakan suatu perasaan senang atau kecewa yang muncul setelah membandingkan antara persepsi atau kesannya terhadap kinerja (hasil) suatu produk yang dihasilkan oleh bank. Kepuasan nasabah sebagai evaluasi pasca konsumsi bahwa suatu alternatif yang dipilih setidaknya memenuhi atau melebihi harapan nasabah. Nasabah berkontribusi pada sejumlah aspek krusial, seperti terciptanya loyalitas pelanggan, meningkatnya reputasi perusahaan, berkurangnya elastisitas 
harga, berkurangnya biaya transaksi masa depan dan meningkatnya efisiensi dan produktivitas nasabah. Kepuasan nasabah terlihat apabilah pelayanan yang diberikan bank sesuai dengan keinginan nasabah.

Banyak perusahaan yang mengandalkan kepuasan konsumen sebagai jaminan keberhasilan dikemudian hari tetapi kemudian kecewa mendapati bahwa para konsumennya yang merasa puas dapat membeli produk pesaing tanpa ragu-ragu (Griffin, 2009).

Sebagai perusahaan milik pemerintah daerah, Bank Aceh sebagai Bank Pembangunan Daerah yang berkomitmen memperkuat diri menjadi bank terkemuka di daerahnya. Bank Aceh melalui layanan kompetitif dengan jaringan yang luas serta dikelola secara profesional dalam rangka mendorong pertumbuhan ekonomi regional, diharapkan mampu menjadi bank yang terkemuka di Aceh. Bank Regional Champion akan dilanjutkan menjadi transformasi Bank BPD seluruh Indonesia diharapkan menjadi juara pada daerah sendiri, sehingga Bank Aceh dapat menjadi Leading Regional Bank di daerah Aceh.

Untuk mendukung tercapainya sasaran transformasi Bank BPD sebagai Regional Champion, dalam setiap tahapannya untuk mengimplementasikan dan mengacu pada tiga pilar yakni, Ketahanan yang kuat, Kemampuan sebagai Agent of Regional Development dan kemampuan melayani kebutuhan masyarakat. Tahun 2014, Bank Aceh telah lebih berusia 41 tahun. Sebuah jejak langkah perjalanan yang tidak bisa dibilang singkat, tumbuh dan berkembangnya Bank Aceh dalam memberikan layanan kepada nasabah, mitra kerja, pemegang saham, serta melayani masyarakat Aceh dan kota Medan.

PT Bank Aceh Cabang Medan memberikan pelayanan mengacu pada pola pelayanan prima (excellent service), yaitu cepat, tepat, mudah, murah dan transparan. Penilaian kualitas pelayanan prima yang banyak mendapat perhatian adalah yang dikenal dengan lima dimensi kualitas pelayanan yang dikemukakan oleh Parasuraman,dkk (dalam Lupiyoadi, 2008) yang mengidentifikasikan sekumpulan atribut-atribut pelayanan secara lengkap yang digunakan sebagai kriteria dalam menilai kinerja pelayanan. Untuk menilai kualitas pelayanan terdiri dari bukti fisik (tangible), kehandalan (reliability), ketanggapan (responsiveness), jaminan (assurance), dan empati (empathy). 
Pelayanan yang diberikan PT Bank Aceh Cabang Medan yaitu ada beberapa nasabah yang menyatakan kurang puas dengan pelayanan yang diberikan oleh karyawan ketika melakukan transaksi seperti karyawan yang bersikap kurang ramah dalam menjawab pertanyaan nasabah, jam pelayanan yang tidak tepat waktu sehingga nasabah harus menunggu karyawan yang belum hadir serta waktu pelayanan yang dianggap menghabiskan waktu yang cukup lama. Bentuk ketidakpuasan tersebut terlihat banyak nasabah yang sudah tidak aktif dalam mengunakan tabungan. Jumlah nasabah yang tidak aktif lagi menggunakan tabungan dapat dilihat pada Tabel 1.

Tabel 1. Data Jumlah Nasabah Yang Tidak Aktif

\begin{tabular}{cccc}
\hline Tahun & $\begin{array}{c}\text { Nasabah } \\
\text { (Orang) }\end{array}$ & $\begin{array}{c}\text { Nasabah Yang Tidak } \\
\text { Melapor (Orang) }\end{array}$ & $\begin{array}{c}\text { Persentase Nasabah Yang } \\
\text { Tidak Melapor } \\
\text { (\%) }\end{array}$ \\
\hline 2011 & 1690 & 672 & 17.43 \\
2012 & 1770 & 545 & 19.28 \\
2013 & 1820 & 453 & 19.83 \\
2014 & 1900 & 703 & 20.70 \\
2015 & 2090 & 853 & 22.77 \\
\hline
\end{tabular}

Sumber: Laporan Tahunan Pelayanan PT Bank Aceh Cabang Medan, 2016

Tujuan penelitian ini adalah:

a) Untuk mengetahui dan menganalisis pengaruh bukti fisik secara langsung terhadap Kepuasan Nasabah pada PT Bank Aceh Cabang Medan.

b) Untuk mengetahui dan menganalisis pengaruh kehandalan secara langsung terhadap Kepuasan Nasabah pada PT Bank Aceh Cabang Medan.

c) Untuk mengetahui dan menganalisis pengaruh ketanggapan secara langsung terhadap Kepuasan Nasabah pada PT Bank Aceh Cabang Medan.

d) Untuk mengetahui dan menganalisis pengaruh jaminan secara langsung terhadap Kepuasan Nasabah pada PT Bank Aceh Cabang Medan.

e) Untuk mengetahui dan menganalisis pengaruh empati secara langsung terhadap Kepuasan Nasabah pada PT Bank Aceh Cabang Medan. 
f) Untuk mengetahui dan menganalisis pengaruh bukti fisik secara langsung terhadap Loyalitas nasabah pada PT Bank Aceh Cabang Medan.

g) Untuk mengetahui dan menganalisis pengaruh kehandalan secara langsung terhadap Loyalitas nasabah pada PT Bank Aceh Cabang Medan.

h) Untuk mengetahui dan menganalisis pengaruh ketanggapan secara langsung terhadap Loyalitas nasabah pada PT Bank Aceh Cabang Medan.

i) Untuk mengetahui dan menganalisis pengaruh jaminan secara langsung terhadap Loyalitas nasabah pada PT Bank Aceh Cabang Medan.

j) Untuk mengetahui dan menganalisis pengaruh empati secara langsung terhadap Loyalitas nasabah pada PT Bank Aceh Cabang Medan.

k) Untuk mengetahui dan menganalisis pengaruh Kepuasan Nasabah secara langsung terhadap Loyalitas nasabah pada PT Bank Aceh Cabang Medan.

1) Untuk mengetahui dan menganalisis pengaruh Bukti fisik, kehandalan, ketanggapan, jaminan dan empati secara tidak langsung terhadap Loyalitas nasabah melalui kepuasan nasabah pada PT Bank Aceh Cabang Medan.

Kotler \& Keller (2009) menyatakan pelayanan (service) adalah semua tindakan atau kinerja yang dapat ditawarkan satu pihak kepada pihak lain yang pada intinya tidak berwujud dan tidak menghasilkan kepemilikan apapun. Menurut Supranto (2006) pelayanan merupakan suatu kinerja penampilan, tidak berwujud dan cepat hilang, lebih dapat dirasakan dari pada dimiliki, serta pelanggan lebih dapat berpartisipasi aktif dalam proses mengkonsumsi pelayanan tersebut.

Menurut Thorik dan Hardiono (2006) pentingnya memberikan pelayanan yang berkualitas disebabkan pelayanan (service) tidak hanya sebatas mengantarkan atau melayani. Service berarti mengerti, memahami dan merasakan sehingga penyampaiannya pun akan mengenai heart share konsumen dan pada akhirnya memperkokoh posisi dalam mind share konsumen. 
Kualitas Pelayanan merupakan tingkat keunggulan untuk memenuhi keinginan pelanggan. Kualitas Pelayanan dinilai berdasarkan presepsi konsumen yang membandingkan harapan untuk menerima layanan dan pengalaman sebenarnya atas layanan yang diterima. Menurut Kotler (2009) Kualitas (quality) adalah totalitas fitur dan karakteristik produk atau pelayanan yang bergantung pada kemampuannya untuk memuaskan kebutuhan yang dinyatakan atau tersirat.

Menurut Supranto (2006), pelayanan merupakan suatu kinerja penampilan, tidak berwujud dan cepat hilang, lebih dapat dirasakan daripada dimiliki, serta konsumen lebih dapat berpartisipasi aktif dalam proses mengkonsumsi pelayanan tersebut. Kotler dan Keller (2009) menyatakan pelayanan Aayanan (service) adalah semua tindakan atau kinerja yang dapat ditawarkan satu pihak kepada pihak lain yang pada intinya tidak berwujud dan tidak menghasilkan kepemilikan apapun.

\section{METODE PENELITIAN}

Jenis penelitian dengan menggunakan deskriptif kuantitatif yaitu untuk mengukur kekuatan hubungan antara dua variabel atau lebih dalam kegiatan mengumpulkan data sebanyak-banyaknya mengenai fakta-fakta yang merupakan pendukung terhadap penelitian. Sifat penelitian dengan explanatory research. Sugiyono (2011) menyatakan bahwa, penelitian explanatory merupakan penelitian yang bermaksud menjelaskan kedudukan variabel yang diteliti serta hubungan antara satu variabel dengan variabel lainnya. Lokasi penelitian dilaksanakan di Kantor PT Bank Aceh Cabang Medan yang ber alamat di Jl. Sisingamangaraja No.19 D-E. Penelitian dilakukan pada bulan Januari 2017 sampai dengan bulan Juli 2017.

Menurut Sugiyono (2011) pengertian populasi adalah wilayah generalisasi yang terdiri atas: objek/subjek yang mempunyai kualitas dan karakteristik tertentu yang ditetapkan oleh peneliti untuk dipelajari dan kemudian ditarik kesimpulannya. Dapat disimpulkan bahwa populasi bukan sekedar jumlah yang ada pada objek atau subjek yang dipelajari, tetapi meliputi seluruh karakteristik atau sifat yang dimiliki oleh subjek atau objek tersebut. Populasi dalam penelitian ini adalah nasabah yang sudah terdaftar di PT Bank Aceh Cabang Medan sejak dari tahun 2014 sampai 
dengan 2015 dengan jumlah 1.500 orang. Dalam menentukan sampel yang dibutuhkan jika ukuran populasi diketahui, maka peneliti menggunakan rumus Slovin sebagai berikut :

$$
\mathrm{n}=\frac{N}{1+N e^{2}}
$$

Keterangan :

$\mathrm{n}=$ Jumlah Sampel

$\mathrm{N}=$ Jumlah Populasi

$\mathrm{e}=$ Tingkat Kesalahan (persen kelonggaran ketidaktelitian karena kesalahan penarikan sampel).

Populasi (N) sebanyak 1.500 orang dan tingkat kesalahan (e) sebesar $10 \%$ maka besarnya sampel adalah : $\mathrm{n}=\frac{1500}{1+1500(0,10)^{2}}=93,75 \approx 94$

Jadi jumlah sampel yang digunakan dalam penelitian ini setelah hasil pembulatan adalah 94 orang. Adapun karakteristik responden yang dijadikan sampel dalam penelitian ini yaitu:

1. Sudah menjadi nasabah selama 1 tahun.

2. Melakukan transaksi berturut-turut selama 3 bulan

Teknik pengambilan sampel dalam penelitian menggunakan Accidental sampling, Teknik pengambilan sampel yang dilakukan kepada pihak responden yang kebetulan berada di tempat (objek) yang akan diteliti.

Berdasarkan sumbernya, data dibedakan menjadi dua, yaitu:

1) Data primer, yakni data yang diperoleh secara langsung dari responden yang terpilih di lokasi penelitian. Data primer diperoleh dengan cara memberikan daftar pertanyaan (questionaire) dan melakukan wawancara.

2) Data sekunder, yakni data yang diperoleh melalui studi dokumentasi yang berasal dari PT Bank Aceh Cabang Medan seperti gambaran umum perusahaan, data nasabah, laporan kinerja perusahaan, buku, jurnal penelitian, majalah, dan situs internet untuk mendukung penelitian ini. 


\section{HASIL DAN PEMBAHASAN}

Berdasarkan hasil penelitian adalah sebagai berikut :

\section{Uji Normalitas}

Uji normalitas digunakan untuk mengetahui sebuah regresi telah berdistribusi normal atau tidak. Uji normalitas data ini dapat diketahui dengan menggunakan diagram pencar dan uji Kolmogorov-Smirnov. Untuk mengetahui hasil uji distribusi normal Kolmogorov-Smirnov dapat dilihat pada Tabel 2 berikut ini :

Tabel 2. Uji Normalitas Data Kolmogorov-Smirnov

One-Sample Kolmogorov-Smirnov Test

\begin{tabular}{llc}
\hline & & Unstandardized Residual \\
\hline $\mathrm{N}$ & & 94 \\
Normal Parameters ${ }^{\mathrm{a}, \mathrm{b}}$ & Mean & .0000000 \\
& Std. Deviation & .85498914 \\
Most Extreme Differences & Absolute & .060 \\
& Positive & .052 \\
& Negative & -.060 \\
Kolmogorov-Smirnov Z & & .582 \\
Asymp. Sig. (2-tailed) & & .887 \\
\hline
\end{tabular}

a. Test distribution is Normal.

b. Calculated from data.

sumber: hasil penelitian, 2017 (data diolah)

Berdasarkan Tabel 2. di atas dapat di ketahui bahwa nilai Asym.Sign (2 Tailed) atau nilai signifikansi sebesar 0,887 lebih besar dari nilai signifikansi $\alpha 0,05$, maka dapat disimpulkan bahwa data terdistibusi secara normal.

\section{Uji Multikolinieritas}

Pada Tabel 3. menunjukkan nilai VIF dan tolerance semua variabel dalam penelitian ini tidak mengalami multikolinieritas. Hal ini ditunjukkan oleh ketiga variabel tersebut yang memiliki nilai VIF lebih kecil dari 10 dan nilai tolerance diatas 0,1 . Hasil pengujian tersebut menunjukkan bahwa dalam model regresi ini seluruh variabel bebas tidak terjadi multikolinieritas. 
Hasil pengujian multikolinieritas dapat dilihat pada Tabel 3. di bawah ini :

Tabel 3. Hasil Uji Multikolinieritas

\begin{tabular}{llcccc}
\hline \multirow{2}{*}{ Model } & \multicolumn{2}{c}{$\begin{array}{c}c \\
\text { L5.0\% Confidence Interval for B }\end{array}$} & \multicolumn{2}{c}{ Collinearity Statistics } \\
& & Lower Bound & Upper Bound & Tolerance & VIF \\
\hline 1 & (Constant) & -1.095 & 1.153 & & \\
& Bukti Fisik & .010 & .259 & .244 & 4.092 \\
Kehandalan & .034 & .368 & .166 & 6.019 \\
Ketanggapan & .012 & .297 & .256 & 3.914 \\
Jaminan & .001 & .219 & .321 & 3.113 \\
Empati & .002 & .332 & .285 & 3.513 \\
\hline
\end{tabular}

a. Dependent Variable: Loyalitas Nasabah

Sumber: Hasil Penelitian, 2017 (data diolah)

\section{Uji Heteroskedastisitas}

Uji heteroskedastisitas bertujuan untuk menguji dalam sebuah model regresi terjadi ketidaksamaan varians dari residual dari satu pengamatan ke pengamatan lainnya. Uji heteroskedastisitas dapat diketahui melalui diagram scatterplot dan uji glejser. Pada uji heteroskedastisitas dengan menggunakan diagram scatterplot deteksi ada atau tidaknya masalah heterokedastisitas dalam suatu model regresi bisa dilakukan dengan melihat pola titik-titik pada satu grafik scatterplot dengan dasar pengambilan keputusan yakni jika ada pola tertentu seperti titik-titik membentuk suatu pola yang teratur maka telah terjadi heterokedastisitas.

Pengaruh Bukti Fisik, Kehandalan, Ketanggapan, Jaminan Dan Empati Terhadap Loyalitas Nasabah Pada PT Bank Aceh Cabang Medan

1. Analisis Persamaan Regresi Berganda

Berdasarkan hasil persamaan regresi berganda pengaruh bukti fisik, kehandalan, ketanggapan, jaminan dan empati terhadap loyalitas nasabah diperoleh hasil seperti dalam Tabel 4. 1:

2. Uji Simultan

Uji simultan/uji F dilakukan untuk mengetahui tingkat signifikansi dengan alpha $<0,05$ dari bukti fisik, kehandalan, ketanggapan, jaminan dan empati 
secara simultan terhadap loyalitas nasabah. Hasil pengujian uji $\mathrm{F}$ pada penelitian ini dapat dilihat pada Tabel 42 :

Tabel 4.1 Hasil Uji Regresi Bukti fisik, Kehandalan, Ketanggapan, Jaminan dan Empati, serta Uji Parsial

\begin{tabular}{|c|c|c|c|c|c|c|}
\hline & \multirow[t]{2}{*}{ Model } & \multicolumn{2}{|c|}{ Unstandardized Coefficients } & \multirow{2}{*}{$\begin{array}{c}\text { Standardized } \\
\text { Coefficients } \\
\text { Beta }\end{array}$} & \multirow[b]{2}{*}{$\mathrm{T}$} & \multirow[b]{2}{*}{ Sig. } \\
\hline & & B & Std. Error & & & \\
\hline \multirow[t]{6}{*}{1} & (Constant) & .029 & .566 & & .051 & .960 \\
\hline & Bukti Fisik & .134 & .063 & .198 & 2.140 & .035 \\
\hline & Kehandalan & .201 & .084 & .269 & 2.395 & .019 \\
\hline & Ketanggapan & .155 & .072 & .195 & 2.151 & .034 \\
\hline & Jaminan & .110 & .055 & .162 & 2.002 & .048 \\
\hline & Empati & .167 & .083 & .173 & 2.017 & .047 \\
\hline
\end{tabular}

a. Dependent Variable: Loyalitas Nasabah

Sumber: Hasil Penelitian, 2017 (data diolah)

Tabel 4.2 Hasil Pengujian Hipotesis Secara Simultan

\begin{tabular}{ccccccc}
\hline & Model & Sum of Squares & Df & Mean Square & F & Sig. \\
\hline \multirow{4}{*}{1} & Regression & 300.825 & 5 & 60.165 & 77.879 & $.000^{\mathrm{a}}$ \\
& Residual & 67.984 & 88 & .773 & & \\
& Total & 368.809 & 93 & & & \\
\hline
\end{tabular}

a. Predictors: (Constant), X5, X4, X3, X1, X2

b. Dependent Variable: Loyalitas Nasabah

Sumber: Hasil Penelitian, 2017 (data diolah)

Pengaruh bukti fisik, kehandalan, ketanggapan, jaminan dan empati terhadap kepuasan nasabah pada PT Bank Aceh Cabang Medan

1. Analisis Persamaan Regresi Berganda

Berdasarkan hasil persamaan regresi berganda pengaruh bukti fisik, kehandalan, ketanggapan, jaminan dan empati diperoleh hasil seperti dalam Tabel 5 :

2. Analisis Persamaan Regresi

Berdasarkan hasil persamaan regresi sederhana pengaruh kepuasan nasabah terhadap loyalitas nasabah diperoleh hasil seperti dalam Tabel 6:

$$
\text { QE Journal |Vol.07 - N o. } 01 \text { M arch } 2018 \text { - } 52
$$


Tabel 5. Hasil Uji Regresi Bukti Fisik, Kehandalan, Ketanggapan, Jaminan dan Empati, serta Uji Parsial

\begin{tabular}{|c|c|c|c|c|c|c|}
\hline & \multirow[t]{2}{*}{ Model } & \multicolumn{2}{|c|}{ Unstandardized Coefficients } & \multirow{2}{*}{$\begin{array}{c}\text { Standardized } \\
\text { Coefficients } \\
\text { Beta }\end{array}$} & \multirow[b]{2}{*}{$\mathrm{t}$} & \multirow[b]{2}{*}{ Sig } \\
\hline & & B & Std. Error & & & \\
\hline \multirow{6}{*}{1} & (Constant) & -.414 & .671 & & -.618 & .538 \\
\hline & Bukti Fisik & .185 & .074 & .254 & 2.491 & .015 \\
\hline & Kehandalan & .216 & .100 & .268 & 2.167 & .033 \\
\hline & Ketanggapan & .194 & .085 & .227 & 2.277 & .025 \\
\hline & Jaminan & .005 & .065 & .008 & .085 & .933 \\
\hline & Empati & .216 & .098 & .207 & 2.197 & .031 \\
\hline
\end{tabular}

a. Dependent Variable: Kepuasan Nasabah

Sumber: Hasil Penelitian, 2017 (data diolah)

Tabel 6 Hasil Uji Regresi Kepuasan Nasabah, serta Uji Parsial

\begin{tabular}{|c|c|c|c|c|c|c|}
\hline & \multirow[t]{2}{*}{ Model } & \multicolumn{2}{|c|}{ Unstandardized Coefficients } & \multirow{2}{*}{$\begin{array}{c}\text { Standardized } \\
\text { Coefficients } \\
\text { Beta }\end{array}$} & \multirow[b]{2}{*}{$\mathrm{t}$} & \multirow[b]{2}{*}{ Sig. } \\
\hline & & B & Std. Error & & & \\
\hline \multirow[t]{2}{*}{1} & (Constant) & 2.102 & .563 & & 3.733 & .000 \\
\hline & $\begin{array}{l}\text { Kepuasan } \\
\text { nasabah Z }\end{array}$ & .791 & .051 & .852 & 15.601 & .000 \\
\hline
\end{tabular}

a. Dependent Variable: Loyalitas Nasabah

Sumber: Hasil Penelitian, 2017 (data diolah)

1. Pengaruh bukti fisik, kehandalan, ketanggapan, jaminan dan empati terhadap loyalitas nasabah

Hasil penelitian menunjukkan secara simultan bukti fisik, kehandalan, Ketanggapan, Jaminan dan empati berpengaruh positif dan signifikan terhadap loyalitas nasabah, kemudian secara parsial masing-masing variabel bukti fisik, Kehandalan, Ketanggapan, Jaminan dan empati berpengaruh signifikan terhadap loyalitas nasabah.

2. Pengaruh bukti fisik, Kehandalan, Ketanggapan, Jaminan dan empati terhadap kepuasan nasabah 
Hasil penelitian menunjukkan secara simultan bukti fisik, Kehandalan, Ketanggapan, Jaminan dan empati berpengaruh signifikan terhadap kepuasan nasabah, kemudian secara parsial masing-masing bukti fisik berpengaruh positif dan signifikan terhadap kepuasan nasabah, kehandalan berpengaruh signifikan terhadap kepuasan nasabah, ketanggapan berpengaruh positif dan signifikan terhadap kepuasan nasabah, jaminan tidak berpengaruh signifikan terhadap kepuasan nasabah dan empati berpengaruh positif dan signifikan terhadap kepuasan nasabah.

\section{Pengaruh kepuasan nasabah terhadap Loyalitas nasabah}

Hasil penelitian menunjukkan kepuasan nasabah berpengaruh positif dan signifikan terhadap Loyalitas nasabah.

4. Pengaruh bukti fisik, Kehandalan, Ketanggapan, Jaminan dan empati dengan kepuasan nasabah sebagai variabel intervening pada PT Bank Aceh Cabang Medan

Hasil penelitian menunjukkan adanya pengaruh tidak langsung bukti fisik, kehandalan, ketanggapan, jaminan dan empati terhadap loyalitas nasabah. Artinya meningkatnya bukti fisik, kehandalan, ketanggapan, jaminan dan empati dapat dilihat dari adanya pengaruh langsung dan tidak langsung bukti fisik, kehandalan, ketanggapan, jaminan dan empati terhadap loyalitas nasabah melalui kepuasan nasabah.

\section{SIMPULAN DAN SARAN}

Berdasarkan hasil penelitian dan pembahasan pada bab sebelumnya maka dapat disimpulkan sebagai berikut:

1. Hasil uji secara simultan menunjukkan bukti fisik, kehandalan, ketanggapan, jaminan dan empati secara bersama-sama berpengaruh positif dan signifikan terhadap loyalitas nasabah pada PT Bank Aceh Cabang Medan. Selain itu bukti fisik, kehandalan, ketanggapan, jaminan dan empati berpengaruh signifikan terhadap kepuasan nasabah pada PT Bank Aceh Cabang Medan, serta Bukti fisik, kehandalan, ketanggapan, jaminan dan empati secara langsung dan tidak langsung berpengaruh positif terhadap Loyalitas nasabah melalui kepuasan nasabah pada PT Bank Aceh Cabang Medan. 
2. Secara parsial bukti fisik berpengaruh positif dan signifikan terhadap kepuasan nasabah, kehandalan berpengaruh positif dan signifikan terhadap kepuasan nasabah, ketanggapan berpengaruh positif dan signifikan terhadap kepuasan nasabah, jaminan tidak berpengaruh positif dan signifikan terhadap kepuasan nasabah dan empati berpengaruh positif dan signifikan terhadap kepuasan nasabah pada PT Bank Aceh Cabang Medan.

3. Kepuasan nasabah berpengaruh positif dan signifikan terhadap loyalitas nasabah pada PT Bank Aceh Cabang Medan.

\section{DAFTAR PUSTAKA}

Griffin, 2009..Customer Loyalty :Loyalty is defined as non random purchase expressed overtime by some decision making unit.

Kotler, K.L.Keller. 2009. Manajemen Pemasaran. Jakarta: Penerbit Erlangga.

Lupiyoandi, Rambat. dan A.Hamdani. 2009. Manajemen Pemasaran Jasa. Edisi Kedua. Jakarta: Salemba Empat.

Sugiyono. 2006. Metode Penelitian Bisnis. Cetakan Keenam. Bandung: Alfabeta.

Thorik, Hardiono. 2006. Marketing. Takbir Publishing House, Bandung. 